\title{
Health-related stakeholders' perceptions of clinical pharmacy services in Qatar
}

\author{
Tesnime Jebara $^{1}$ (D) Scott Cunningham ${ }^{1} \cdot$ Katie MacLure $^{1} \cdot$ Ahmed Awaisu $^{2} \cdot$ Abdulrouf Pallivalapila $^{3} \cdot$ Moza Al Hail $^{3}$. \\ Derek Stewart ${ }^{2}$
}

Received: 12 December 2019 / Accepted: 25 July 2020 / Published online: 22 September 2020

(c) The Author(s) 2020

\begin{abstract}
Background In Qatar, the National Vision 2030 and the National Health Strategy 2018-2022 articulate the need to improve healthcare delivery by better utilisation of the skilled workforce. In this regard, pharmacy practice is rapidly advancing and several extended pharmacy services are now available in institutionalised settings. Objective This study aimed to determine health-related stakeholders' perceptions of current clinical pharmacy services in Qatar, and the potential development and implementation of further patient-centred roles. Setting All major organisations and institutions relating to the practice, education, regulation, and governance of pharmacy in Qatar. Method Qualitative, face-to-face semi-structured interviews were conducted with individuals in key strategic positions of policy development and influence (i.e. health-related academic leaders, healthcare policy developers, directors of medicine/pharmacy/nursing, and patient safety leaders). Participants were recruited via a combination of purposeful and snowball sampling, until the point of data saturation was reached. The interview guide was grounded in the Consolidated Framework for Implementation Research domains of innovation characteristics, outer and inner setting, characteristics of individuals, and implementation process. The interviews were digitally recorded, transcribed and independently analysed by two researchers using the Framework approach. Main outcome measure Perceptions of stakeholders regarding current and potential for future clinical pharmacy services in Qatar. Results Thirty-seven interviews were conducted with stakeholders of policy influence in healthcare. The interviewees reported a variety of clinical pharmacy services available in Qatar, which they perceived as positively impacting patient care outcomes, pharmacists' professional autonomy, and the healthcare system in general (innovation characteristics). However, they perceived that these services were mainly performed in hospitals and less in community pharmacy setting (inner setting) and were undervalued by patients and the public (outer setting). Expansion of pharmacists' clinical activities was supported, with recognition of facilitators such as the skillset and training of pharmacists, potential time release due to automation and well-considered implementation processes (characteristics of individuals, inner setting, process). Conclusion Health-related stakeholders in Qatar have positive perceptions of current clinical pharmacy services and support the expansion of pharmacist's roles. However, service development needs to consider the issues of patient and public awareness and initially target institutionalised healthcare settings.
\end{abstract}

Keywords Pharmacy practice $\cdot$ Clinical pharmacy $\cdot$ Service evaluation $\cdot$ Theory $\cdot$ Middle east $\cdot$ Qualitative study

\section{Impacts on practice}

Tesnime Jebara

jebtesnime@gmail.com

1 School of Pharmacy and Life Sciences, Robert Gordon University, The Sir Ian Wood Building, Garthdee Road, Aberdeen AB10 7GJ, UK

2 College of Pharmacy, QU Health, Qatar University, Doha, Qatar

3 Pharmacy Department, Women's Wellness and Research Center, Hamad Medical Corporation, Doha, Qatar
- In Qatar, pharmacy practice is rapidly advancing and several extended clinical pharmacy services are now available in institutionalised healthcare settings.

- However, limited evidence is available to explore how key health-related stakeholders perceive these services including the potential development and implementation of new patient-centred pharmacist's roles. 
- Findings of this research could facilitate cognitive pharmaceutical service development and better provision of patient-centered care, which could be transferrable to other countries, especially from the context of the Middle East.

\section{Introduction}

The evolution from product focused pharmacy services to more patient-centred pharmacy services was articulated in World Health Organization (WHO) policy documents advocating better use of pharmacists' skills to improve health care [1-3]. Similarly, the International Pharmaceutical Federation (the global body representing pharmacy, pharmaceutical sciences and pharmaceutical education) advocates the systematic development and implementation of more clinical patient-centred and outcomes-oriented services $[4,5]$.

Several countries have well-developed clinical pharmacy services which are part of routine practice. For instance, in the United Kingdom (UK), clinical pharmacy services have evolved from rarely providing therapeutic drug monitoring and medication history-taking to the introduction of supplementary prescribing in 2003 and independent prescribing in 2006 [6, 7]. The majority of literature evaluating pharmacist prescribers' practice demonstrates safety, the achievement of clinical outcomes comparable to physicians $[8,9]$ and acceptability by a range of key health stakeholders $[10,11]$. In 2015, the UK launched an ambitious plan aiming to embed clinical pharmacists within general medical practices $[12,13]$. An independent evaluation based on pilot data from England confirms the significant contribution to patient safety, supporting long-term condition management, and improving medication knowledge within the team [14]. Similar positive results have been reported in Scotland, where pharmacists are now practising within one-third of general medical practices [15].

Over the past decade, Qatar has taken steps to transform its healthcare system. The Qatar National Vision 2030 aims to "transform Qatar into an advanced country by 2030 , capable of sustaining its own development and providing for a high standard of living for all of its people for generations to come" by "balancing the accomplishments that achieve economic growth with the human and natural resources" [16]. To realise the ambitions of the National Vision for a healthy population, the National Health Strategy was launched in 2011 [17]. Six projects were initiated, one of which aimed to strengthen the role of pharmacists in supporting patients, as well as improving the quality of healthcare system by making it more accessible and less costly. Recently, the Ministry of Public Health reinforced the shift in care provision from secondary and tertiary care to primary care in an updated National Health Strategy 2018-2022, "Our Health, Our Future: Improved health for Qatar's population, meeting the needs of existing and future generations" [18].

Healthcare in Qatar is provided through governmentfunded and private-provided secondary and tertiary institutions, government-funded primary healthcare centres and private sector centres (ambulatory care), and community pharmacies (Fig. 1) [19].

Hamad Medical Corporation (HMC) is the largest provider of healthcare in Qatar, and is regarded as one of the leading hospital services providers in the Middle East region. HMC manages 12 hospitals-nine specialist hospitals and three community hospitals - as well as the National Ambulance Service and home and residential care services [21]. In 2016, HMC became the first healthcare system across the globe to have all its hospitals accredited by Joint Commission International (JCI) under the Academic Medical Center accreditation program [21].

Pharmacy practice in Qatar has advanced in recent years due to multiple factors including the establishment of the first national college of pharmacy in 2007 [22]. As at 2013, the number of pharmacists registered in Qatar was 1023 in the public and 991 in the private sectors giving an estimated 1.01 pharmacists per 1000 population [23, 24]. There is some evidence that pharmacy services are evolving toward clinical, patient-centred roles [25]. HMC has implemented a pharmacist-led anticoagulation clinic, with initial positive

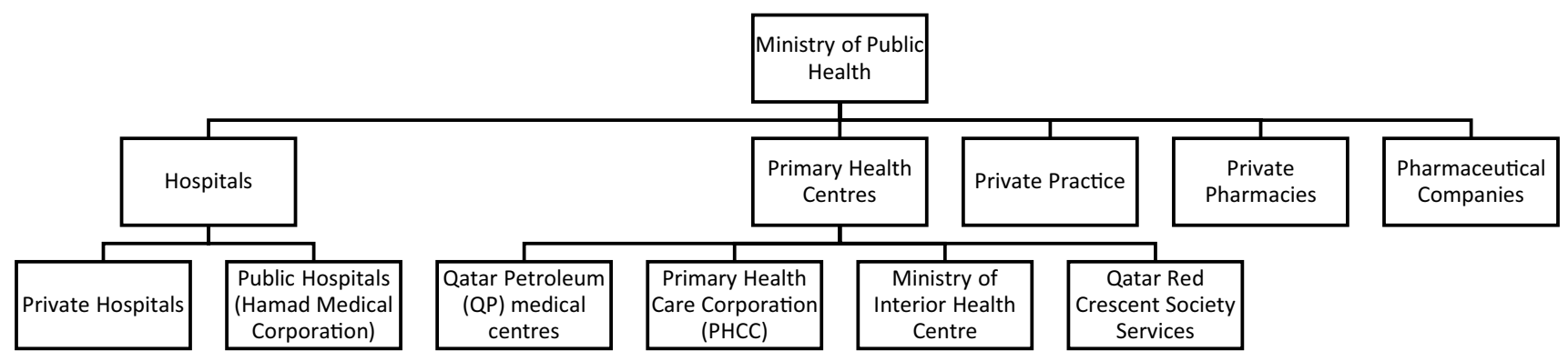

Fig. 1 Healthcare system in Qatar [20] 
findings for clinical outcomes of time in therapeutic range (TTR), percentage of visits within therapeutic range and reduced percentage of visits with extreme subtherapeutic international normalized ratio (INR) [22, 26]. Therefore, pharmacy practice is rapidly advancing and several extended pharmacy services are now available in institutionalised settings in Qatar. There, however, remains potential for expanding further clinical pharmacy services to all sectors of practice. Obtaining the perceptions of key decision-makers (stakeholders) would facilitate plans for expansion.

\section{Aim of the study}

This study aimed to determine health-related stakeholders' perceptions of current clinical pharmacy services in Qatar, and the potential development and implementation of further patient-centred roles.

\section{Ethics approval}

Ethical approval was granted by Robert Gordon University School of Pharmacy and Life Sciences Research Ethics Committee (Approval reference S64), Ministry of Public Health Ethics Committee, Hamad Medical Corporation Medical Research Committee (Approval reference MRC0449/2017), and Qatar University Institutional Review Board (Approval reference QU-IRB 772-E/17).

\section{Methods}

\section{Study design}

This study utilised a qualitative approach of semi-structured interviews with key stakeholders. A qualitative methodology was selected to generate in-depth, rich data allowing detailed description and understanding of perceptions around clinical pharmacy practice in Qatar [27].

\section{Setting}

Data generation took place across all major organisations and institutions relating to the practice, education, regulation, and governance of pharmacy practice in Qatar. These comprised of the Ministry of Public Health; primary, secondary and tertiary healthcare institutions; community pharmacies; and all healthcare academic institutions providing pharmacy, medical, nursing, and pharmacy technician education programmes.

\section{Inclusion and exclusion criteria}

The intention was to generate data representing all key stakeholder groups, with policy influence relating to the development, implementation and evaluation of clinical models of care. The groups targeted were individuals in key strategic positions of policy influence (i.e. health-related academic leaders, healthcare policy developers, directors of medicine/ pharmacy/nursing, and patient safety leaders). Members of the research team based in Qatar, who might have satisfied the above criteria, were excluded from the study.

\section{Sampling and sampling approach}

The sampling frame included all individuals meeting the inclusion and exclusion criteria. The names and contact details of all potential participants were collated by the research team members using their professional networks. Purposive sampling was employed to capture those individuals who were most likely to contribute to the achievement of the research objectives. Snowball sampling was also utilised to ensure that no key individuals had been omitted by asking each interviewee to recommend others that they thought were important to include. Sample size was determined to achieve data saturation according to the steps outlined by Francis et al. [28] Five members from each professional group were interviewed as the initial analysis sample. This sample was believed to represent adequate diversity based on the participants' professions. Afterwards, one additional interview was performed for each professional group before the stopping criterion was tested. Responses were coded and analysed independently by two research team members in order to confirm that data saturation was achieved.

\section{Development of interview guide}

The semi-structured interview guide was constructed based on a review of the published literature on pharmacy practice and grounded in the Consolidated Framework for Implementation Research (CFIR) [29]. This theoretical framework was used to ensure that all relevant implementation factors that can determine the success or failure of any innovation are deliberated. The guide was developed and mapped against the five main domains of CFIR: innovation characteristics (of the intervention being implemented into a particular organisation), outer setting (i.e. economical, political, and social context within which an organisation resides), inner setting (i.e. structural, political, and cultural context through which implementation process will proceed), characteristics of individuals (who will enact the intervention), and process (of implementation) [29]. The interview guide included questions related to participants' awareness of current clinical roles performed by pharmacists in Qatar, their views on 
the efficiency of these services and any potential roles pharmacists in Qatar can perform in the future. The guide was reviewed for dependability, which is the degree to which different researchers are able to produce the same data [30], by members of the research team prior to piloting with five academic and practice-based stakeholders. This pilot process did not lead to any major changes to the guide. Pilot interviews were not included in the dataset.

\section{Data generation}

All potential participants were e-mailed the information leaflet, with a reminder sent 2 weeks later if no response had been received. The interviews were conducted from April to August 2017 by one of the research team members (TJ) who was trained in conducting qualitative research. Written, informed consent was obtained from all research participants before commencing. Interviews, of approximately 45-60 min, were audio-recorded and later transcribed by $\mathrm{TJ}$ and reviewed for accuracy by DS. All interviewees were offered the opportunity to review the transcripts to promote credibility and dependability [30].

\section{Data analysis}

Thematic analysis was conducted using the framework approach following the steps outlined by Ritchie and Spencer [31]. All interviews were input into NVivo ${ }^{\circledR}$ software then initially coded by TJ based on the different constructs of the CFIR before being examined for further sub-themes within each construct. Afterwards, the emerging themes were reviewed against the original data then indexed and refined. The analysis was reviewed by another team member to ensure credibility, with any disagreements resolved through discussion.

\section{Results}

\section{Stakeholders recruitment}

Out of 74 stakeholders invited, 37 interviews were conducted to reach data saturation in each stakeholder group giving representation of all practice settings (Table 1).

\section{Key themes that emerged from the interviews}

Themes which emerged during the interviews were mapped to the different CFIR domains. The major themes frequently highlighted by interviewees are described in more details below while the rest are summarised in Table 2. There were no marked differences in responses across the professional groupings.
Table 1 Characteristics of included stakeholders according to practice setting

\begin{tabular}{ll}
\hline Stakeholders' category & Setting: number of participants* \\
\hline Academic leaders & Medicine: 2 \\
& Pharmacy and Pharmacy technician: 5 \\
& Nursing: 2 \\
Healthcare policy developers & Primary care/Community: 1 \\
& Secondary care: 1 \\
& Tertiary care: 2 \\
& Corporate/Ministry: 2 \\
& Primary care/Community: 1 \\
Medical practice leaders & Secondary care: 3 \\
& Tertiary care: 5 \\
& Corporate/Ministry: 1 \\
& Primary care/Community: 3 \\
Pharmacy practice leaders & Secondary care: 1 \\
& Tertiary care: 3 \\
& Corporate/Ministry: 1 \\
& Secondary care: 1 \\
Nursing practice leaders & Tertiary care: 5 \\
& Corporate/Ministry: 3 \\
& Primary care/Community: 1 \\
Patient safety advocates & Secondary care: 1 \\
& Tertiary care: 4 \\
\hline
\end{tabular}

*Some held multiple roles within their organisation

Interviewees noted a significant evolution in clinical pharmacy services in Qatar, illustrated by the continuous implementation of new services such as the pharmacistrun anticoagulation clinic with advantages to patients and pharmacists themselves (CFIR domain: innovation characteristics). These developments were perceived as being carefully planned with clear communications, guidelines, and monitoring processes (CFIR domain: process). The interviewees perceived that these services were mainly performed in hospitals and less in community pharmacy setting (CFIR domain: inner setting). However, a lack of patient and public awareness regarding clinical pharmacy activities was also highlighted (CFIR domain: outer setting). In addition, some stakeholders reported that the majority of clinical pharmacy services were performed exclusively in hospitals with community pharmacy setting mainly focused on traditional pharmacist's product-oriented role of drugs dispensing. Nevertheless, the interviewees highlighted the potential for further development, aligned to the Qatar National Vision and supported by healthcare leaders (CFIR domain: inner setting). They also commented on the quality of the education and training of pharmacists and the strict licensing requirements to practice in Qatar (CFIR domain: characteristics of individuals).

Given that most discussion (based on counts and depth of discussion) centred on specific CFIR domains and constructs, these are considered in more detail. These were: innovation source (perception of key stakeholders about 


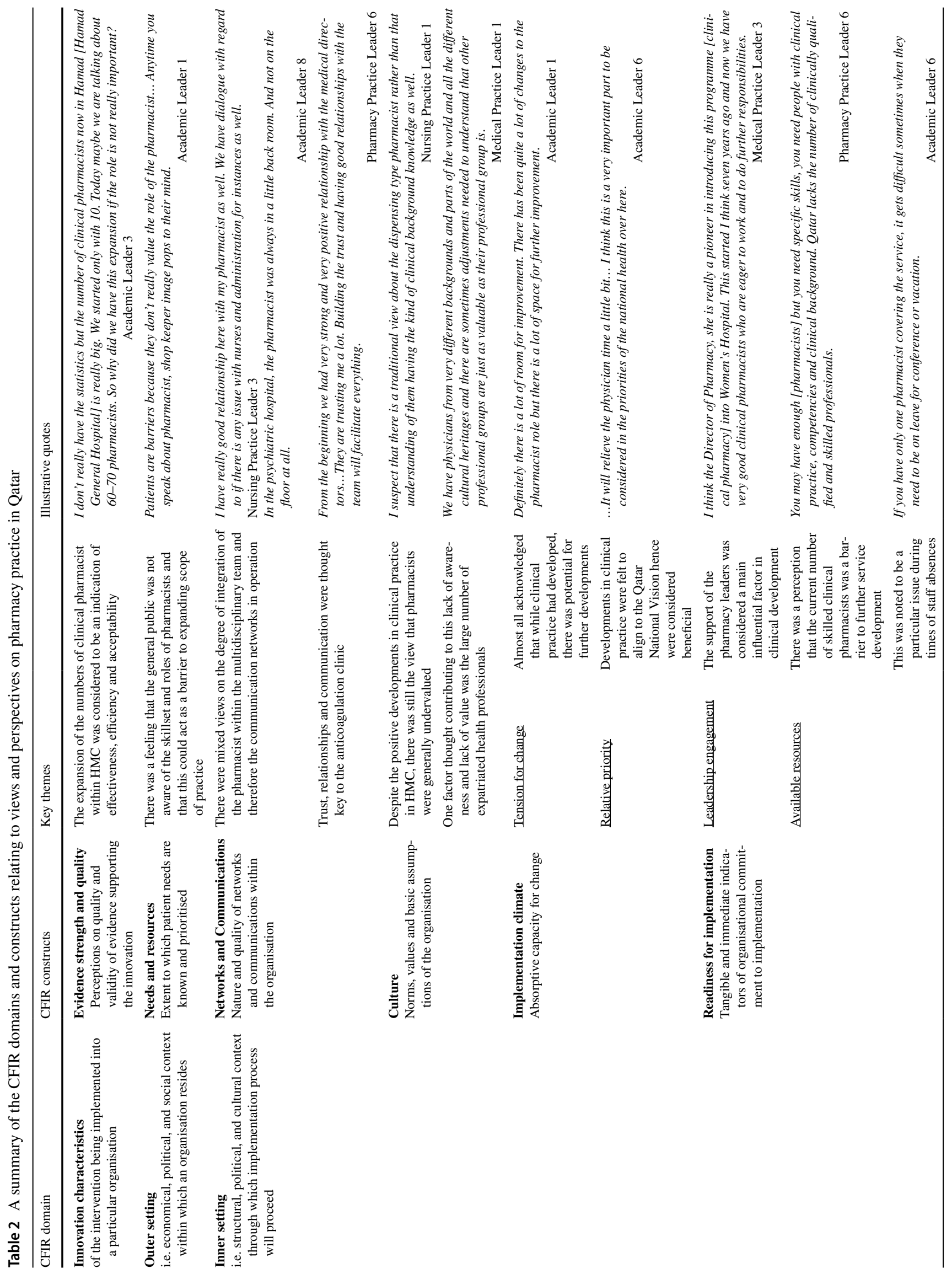




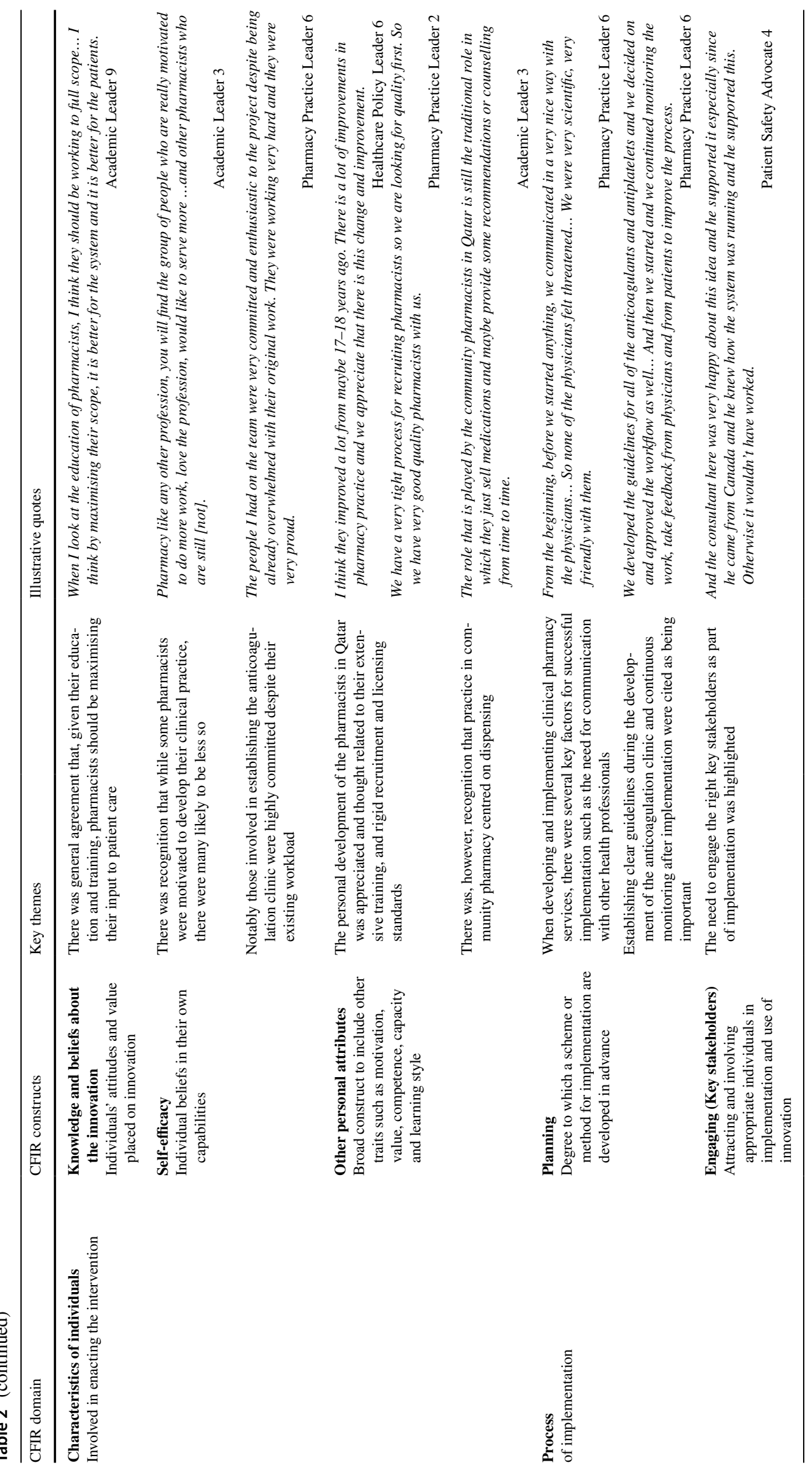


whether the intervention is externally or internally developed); relative advantage (stakeholders' perception of the advantage of implementing the intervention versus an alternative solution); design quality and packaging (perceived excellence in how the intervention is bundled, presented, and assembled); structural characteristics (the social architecture, age, maturity, and size of an organization); and compatibility (the degree of tangible fit between meaning and values attached to the intervention by involved individuals, how those align with individuals' own norms, values, and perceived risks and needs, and how the intervention fits with existing workflows and systems).

\section{Innovation characteristics}

In terms of the innovation of clinical pharmacy practice, there was recognition that this was developing at pace, particularly within HMC. There was description of the clinical pharmacy service in general and exemplified through specialist activities such as the pharmacist-led anticoagulation clinic.

\section{Innovation source}

There was recognition that the anticoagulation service had developed significantly in recent years. This was expressed by participants from all stakeholder groups.

The clinical pharmacists' role has developed quite significantly in recent years like, for example, in [Name]

Hospital there is the anticoagulation clinic that is run by pharmacists.

Academic Leader 1

The clinical service had extended to allow dose adjustment.

We call it the anticoagulation clinic where the clinical pharmacists are on the front line, meeting the patients...checking the INR and then adjusting the dose, so they make the decision.

Medical Practice Leader 5

There was recognition of other HMC clinical services.

Also in clozapine clinic in mental health, there is a direct contact with the patient for monitoring the side effects and recording if require changing the dose...

Pharmacy Practice Leader 4

\section{Relative advantage}

Clinical practice was perceived to bring advantages including professional autonomy, which was considered important to further developments.
... it will give you more confidence in what you are doing, your clinical skills, would help increase the trust that is given to the pharmacists and maybe help them gain more roles in the future.

Academic Leader 6

There were also examples of positive feedback from patients at HMC.

Generally our feedback with like warfarin clinics and such that we have is very positive... patients don't wait for months to get an appointment.

Healthcare Policy Leader 2

This clinical service was also reported to reduce pressure on physicians.

The most important advantage I see from the side of physicians is that it will free their time to do more skilled work.

Academic Leader 6

There was also the view that patient health outcomes were improving.

We can see definitely that the anticoagulation outcomes have been better with those monitored by pharmacists.

Academic Leader 6

\section{Design quality and packaging}

Mandatory continuing professional development for pharmacists was considered a positive development, contributing to the quality of services.

I think they are efficient. They keep continuous education so they have weekly sessions so they are updating themselves.

Healthcare Policy Leader 1

Furthermore, those involved in the delivery of new and specialised services had to undertake further education and training.

It is a condensed course that focuses on anticoagulation, how to dose, what are the guidelines available and the pathophysiology.

Pharmacy Practice Leader 3

While these developments were in HMC settings, it was highlighted that they could also be in others such as in primary healthcare centres.

They don't have it in primary healthcare, the warfarin clinic. But if the volume of patients increase, it can be in primary healthcare, why not?

Medical Practice Leader 5 


\section{Inner setting}

\section{Structural characteristics}

Many participants highlighted that while the public sector was highly regulated with focus on quality of care, the private sector was profit-oriented.

The public sector I think it is more structured because they are accredited... but in private, nothing. They don't have the policies, they don't have guidelines, they are more or less looking for money.

Healthcare Policy Leader 3

There were contradictory views around the influence and power of the medical profession around these developments in clinical pharmacy practice.

It is still completely physician driven. There is still a hierarchy.

Academic Leader 8

In the cancer centre they have a very intimate collaboration with them [physicians] and communication and they really are valued [as an] equivalent member of the team. There is no hierarchy.

Medical Practice Leader 1

One overwhelming theme was that clinical pharmacy practice varied greatly with setting. There was recognition that HMC was much further advanced than other settings.

As for practice, hospitals are better than community since community is not well developed because it lacks assessment and clinical practice.

Pharmacy Practice Leader 6

In primary healthcare centres, they are developing now, they are in a better position if you compare them to the community pharmacists. But I have to say that still they need to work more on themselves. Academic Leader 3

\section{Implementation climate}

\section{a. Compatibility}

There was some appreciation that the clinical pharmacy services in HMC could be benchmarked to practice in western countries.

I left the UK thinking that I had a very good pharmacy service. I have come to Qatar and there is a better pharmacy service here in my view.

Healthcare Policy Leader 5
The level of technology and automation available within HMC was considered a positive facilitator of development.

The level of automation that goes into packages like Cerner is clearly already demonstrating that pharmacists can take on a more assertive role on behalf of the patients to protect their safety...

Healthcare Policy Leader 4

While the clinical anticoagulation clinic was well-established, it was noted that this took time, with acceleration once physicians had evidence of positive outcomes.

At the beginning, when they don't have much experience with it, they may be a little bit suspicious... but then after a while, after they saw our abilities and how really the patients have been stable and monitored appropriately, I think they got more and more confident.

Academic Leader 6

\section{Discussion}

Key stakeholders in Qatar perceived clinical pharmacy services as having a positive impact on patients' outcomes, pharmacists' professional autonomy, and the overall healthcare system. However, interviewees did highlight differences in the extent of the implementation with tertiary and secondary public care (mainly HMC) being the most advanced. Interviewees perceived a lack of awareness of the extent of knowledge, training and practice of pharmacists in Qatar and that pharmacists were undervalued by patients and the public. There was potential to advance clinical pharmacy services, with recognition of facilitators such as the skillset and training of pharmacists, potential time release due to automation and well-considered implementation processes.

Pharmacists' contribution to the healthcare system, the multidisciplinary team and thus patient care, aligns to the aspirations of the Qatar National Vision [16], its associated health strategies $[17,18]$ and international efforts for advancing patient-centred pharmacy practice [1-5].

Several aspects of healthcare setting emerged in this study as being key to the development and perceived success of patient-centred clinical pharmacy services, relating to CFIR domains of innovation characteristics, inner setting, outer setting, characteristics of individuals and process. This is not unique to Qatar, with the WHO and the International Pharmaceutical Federation highlighting that services are most likely to advance in secondary and tertiary care settings [3]. There are several likely contributory factors, including close multidisciplinary collaboration stimulating mutual trust and respect, ease of access to patient data and other key resources, peer support, leadership and aspects 
of governance including role definition, education, training and continuing professional development. Tonna et al. [32] noted the importance of these factors in defining a guide to planning the implementation of pharmacist prescribing, an example of a clinical pharmacy service, in UK hospital practice.

Barriers for clinical pharmacy implementation in primary care such as lack of awareness of pharmacists' skillset and their potential clinical roles were also reported in a qualitative study in Canada [33]. The study highlighted that healthcare professionals were generally unaware of clinical pharmacy roles, which subsequently affected implementation. Similar findings were also reported in relation to the community setting. For instance, a systematic review of factors influencing national implementation of innovations within community pharmacy described three key influences which are: pharmacy staff engagement with the proposed services, operationalisation of the innovations (including design, complexity and resources needed), and pharmacy staff relationships with patients and other healthcare professionals [34]. Thus, there is a need to improve the provision of clinical pharmacy services in primary and community settings which should take into consideration theoretical frameworks, such as the CFIR, which highlight the importance of thorough development and the need for piloting and continuous evaluation in order to ensure the successful implementation of any future clinical pharmacy roles [29].

Pharmacist role expansion was facilitated mainly by the perceived level of education, training, and motivation that pharmacists possess which can further enable them to provide more clinical services in the future (CFIR domain: characteristics of individuals). This could be attributed to the increased focus on developing pharmacists' skills in Qatar highlighted in the National Vision and National Health Strategy and evidenced by the level of pharmacy education offered in the state, the rigorous accreditation, licensing and continuous education training pharmacists in Qatar must undergo [22]. Similar facilitators related to pharmacists' characteristics, mainly their motivation and knowledge, were also reported in a qualitative study with health-system pharmacists and managers who experienced the implementation of clinical pharmacy services in Brazil, highlighting the importance of having a skilled workforce for the successful implementation of such roles [35].

Implementing more advanced clinical pharmacy services, such as the pharmacist-managed anticoagulation clinic, was noted to be met with some resistance that was quickly overcome post-implementation. Zaidan et al. [36] also reported that physicians were more likely to accept new roles performed by pharmacists if they had exposure to these contemporary pharmacy services. These findings were also reported in the UK when pharmacists advocated for a prescribing role in relation to physicians' concerns around liability and pharmacists' abilities to perform such a role [11]. These findings highlight the importance of the lived experiences and the need for thorough planning and involvement of key stakeholders which also constitutes a key domain of CFIR thus highlighting the need to use a theoretical framework in the early development of any new innovation.

Despite these advances in clinical pharmacy services in Qatar, interviewees noted that the lack of public understanding of pharmacists' knowledge, training and services in general is a major barrier to further role development especially within community pharmacy setting where pharmacists are considered to be drug dispensers (CFIR domain: outer setting). Low public or patient awareness of extended pharmacy services in the community pharmacy setting was also reported to be a common finding in the UK according to a recent systematic review of the current research literature focusing on perspectives on existing and future community pharmacy services [37]. This was often related to lack of exposure or utilisation of community pharmacy services. Thus, there is a great need to improve the public's awareness of the real extent of pharmacists' knowledge and skillset as well as the different roles they perform in order to allow them to expand their clinical services. This was considered especially important in Qatar where pharmacists are advocating for more clinical roles including prescribing. Recent studies have shown that key health stakeholders supported implementation of pharmacist prescribing in Qatar if additional training was provided and more efforts were made to increase awareness of the different services pharmacists provide in order to overcome potential resistance [20, 38].

This was a theory-driven, qualitative study generating in-depth, rich data of stakeholders' perceptions. Steps were taken to enhance the trustworthiness (credibility and dependability) of the research data and findings, including adopting appropriate, well-recognised research methods, encouraging interviewees to be frank and talk freely and use of different researchers to independently analyse data. The key limitations are that the research outcomes are perceptions of stakeholders, rather than objective measures of service outcomes and that the findings may not be transferable beyond Qatar.

Further research should focus on the systematic development, implementation and evaluation of any future clinical pharmacy service development in Qatar.

\section{Conclusion}

Health-related stakeholders in Qatar have positive perceptions of current clinical pharmacy services and support the expansion of pharmacist's roles. However, service development needs to consider the issues of patient and public awareness and initially target hospital settings. 
Acknowledgements The authors would like to thank all the participants that took part in this study for all their time and valuable input.

Funding None.

\section{Conflicts of interest None.}

Open Access This article is licensed under a Creative Commons Attribution 4.0 International License, which permits use, sharing, adaptation, distribution and reproduction in any medium or format, as long as you give appropriate credit to the original author(s) and the source, provide a link to the Creative Commons licence, and indicate if changes were made. The images or other third party material in this article are included in the article's Creative Commons licence, unless indicated otherwise in a credit line to the material. If material is not included in the article's Creative Commons licence and your intended use is not permitted by statutory regulation or exceeds the permitted use, you will need to obtain permission directly from the copyright holder. To view a copy of this licence, visit http://creativecommons.org/licenses/by/4.0/.

\section{References}

1. World Health Assembly. Role of the pharmacist in support of the WHO revised drug strategy. [online]. NK: World Health Organization; 1994. https://apps.who.int/iris/handle/10665/177380. Accessed 24 Sept 2019

2. World Health Organization. Good pharmacy practice (GPP) in community and hospital pharmacy settings. [online]. NK: World Health Organization; 1996. https://apps.who.int/medicinedocs/ documents/s21088en/s21088en.pdf. Accessed 24 Sept 2019.

3. Wiedenmayer K, Summers R, Mackie C, Gous A, Everard M, Tromp D. Developing pharmacy practice: a focus on patient care. [online]. The Netherlands: World Health Organization and International Pharmaceutical Federation; 2006. http://apps. who. int/medicinedocs/documents/s14094e/s 14094e.pdf. Accessed 29 July 2019.

4. International Pharmaceutical Federation. Good pharmacy practice in developing countries: recommendations for stepwise implementation. [online]. The Netherlands: International Pharmaceutical Federation; 1997. https://www.fip.org/files/fip/Statements/ GPP\%20recommendations.pdf. Accessed 24 Sept 2019.

5. International Pharmaceutical Federation. Joint FIP/WHO guidelines on good pharmacy practice: standards for quality of pharmacy services. [online]. The Netherlands: International Pharmaceutical Federation and World Health Organisation; 2012. https ://www.fip.org/file/1476 Accessed 24 Sept 2019.

6. Cotter SM, Barber ND, McKee M. Survey of clinical pharmacy services in United Kingdom National Health Service hospitals. Am J Hosp Pharm. 1994;51(21):2676-84.

7. Cope L, Abuzour A, Tully M. Nonmedical prescribing: where are we now? Ther Adv Drug Saf. 2016;7(4):165-72.

8. Baqir W, Crehan O, Murray R, Campbell D, Copeland R. Pharmacist prescribing within a UK NHS hospital trust: nature and extent of prescribing, and prevalence of errors. Eur J Hosp Pharm. 2015;22:79-82.

9. Weeks G, George J, Maclure K, Stewart D. Non-medical prescribing versus medical prescribing for acute and chronic disease management in primary and secondary care. Cochrane Database of Syst Rev. 2016;11:CD011227.

10. Stewart D, Jebara T, Cunningham S, Awaisu A, Pallivalapila A, Maclure K. Future perspectives on nonmedical prescribing. Ther Adv Drug Saf. 2017;8(6):183-97.
11. Jebara T, Cunningham S, Maclure K, Awaisu A, Pallivalapila A, Stewart D. Stakeholders' views and experiences of pharmacist prescribing: a systematic review. Br J Clin Pharmacol. 2018;84:1883-905.

12. NHS England. General practice forward view. [online]. London: NHS England; 2016. https://www.england.nhs.uk/wp-content/ uploads/2016/04/gpfv.pdf. Accessed 10 Sept 2019.

13. Scottish Government. Supporting information pack-primary care fund pharmacists in GP practices. [online]. Edinburgh: Scottish Government; 2016. https://www2.gov.scot/Resource/0050/00500 253.pdf. Accessed 11 Oct 2019.

14. Mann C, Anderson C, Avery A, Waring J, Boyd M. Clinical pharmacists in general practice: pilot scheme independent evaluation report: full report. [online]. Nottingham: University of Nottingham; 2018. https://www.nottingham.ac.uk/pharmacy/ documents/generalpracticeyearfwdrev/clinical-pharmacists-ingeneral-practice-pilot-scheme-full-report.pdf. Accessed $10 \mathrm{Sept}$ 2019.

15. Stewart D, Anthony B, Morrison C, MacRae Y, Dixon L, Friel E, Yoong E, Cunningham S, Maclure K. Evaluating pharmacist input into the pharmaceutical care of patients in dispensing medical practices in remote and rural areas of Scotland. Fam Pract. 2017;34(4):491-9.

16. Qatar General Secretariat for Development Planning and Statistics. Qatar National Vision 2030.. [online]. Doha: Qatar General Secretariat for Development Planning and Statistics; 2008. http://www.gsdp.gov.qa/portal/page/portal/gsdp_en/qatar_natio nal_vision. Accessed 10 Jan 2016.

17. Qatar Supreme Council of Health. National health strategy 2011-2016. [online]. Doha: Qatar Supreme Council of Health; 2013. http://www.qu.edu.qa/pharmacy/components/upcoming _ events_material/Qatar_National_Health_Strategy.pdf. Accessed 10 Jan 2016.

18. Qatar Ministry of Public Health. National Health Strategy 2018-2022. [online]. Doha: Qatar Ministry of Public Health; 2018. https://www.moph.gov.qa/HSF/Pages/NHS-18-22.aspx. Accessed 10 June 2018.

19. Qatar Supreme Council of Health. Qatar healthcare facilities master plan 2013-2033. [online]. Doha: Qatar Supreme Council of Health; 2014. https://www.moph.gov.qa/HSF/Documents/ QHFMP\%20-\%20Report\%20(1).pdf. Accessed 29 July 2019.

20. Jebara T, Cunningham S, Maclure K, Pallivalapila A, Awaisu A, Al Hail M, Stewart D. Key stakeholders' views on the potential implementation of pharmacist prescribing: a qualitative investigation. Res Social Adm Pharm 2019. (in press). https:// www.sciencedirect.com/science/article/pii/S15517411193015 48?via\%3Dihub. Accessed 20 Jun 2019.

21. Hamad Medical Corporation. About us. [online]. Doha: Hamad Medical Corporation; 2019. https://www.hamad.qa/EN/About -Us/Pages/default.aspx. Accessed 17 Sept 2019.

22. Kheir N. Pharmacy practice in Qatar. In: Fathelrahman A, Ibrahim M, Wertheimer A, editors. Pharmacy practice in developing countries: achievements and challenges. London: Elsevier Inc.; 2016. p. 233-52.

23. Qatar Ministry of Development Planning and Statistics. Health services statistics. [online]. Doha: Qatar Ministry of Development Planning and Statistics; 2013. https://www.psa.gov.qa/ en/statistics $1 /$ pages/topicslisting.aspx?parent $=$ General\&child $=$ StatisticalAbstract. Accessed 29 Mar 2016.

24. Qatar Supreme Council of Health. Qatar health report. [online]. Doha: Qatar Supreme Council of Health; 2013. http://www. nhsq.info/app/media/2941. Accessed 30 Mar 2016.

25. Kheir N, Fahey M. Pharmacy practice in Qatar: challenges and opportunities. South Med Rev. 2011;4(2):92-6.

26. Elewa H, Jalali F, Khudair N, Hassaballah N, Abdelsamad O, Mohammed S. Evaluation of pharmacist-based compared to 
doctor-based anticoagulation management in Qatar. J Eval Clin Pract. 2016;22(3):433-8.

27. Jensen EA, Laurie C. Doing real research: a practical guide to social research. 1st ed. London: Sage Publications; 2016.

28. Francis J, Johnston M, Robertson C, Glidewell L, Entwistle V, Eccles MP, Grimshaw JM. What is an adequate sample size? Operationalising data saturation for theory-based interview studies. Psychol Health. 2010;25(10):1229-45.

29. Damschroder LJ, Aron DC, Keith RE, Kirsh SR, Alexander JA, Lowery JC. Fostering implementation of health services research findings into practice: a consolidated framework for advancing implementation science. Implement Sci. 2009;4:50.

30. Hannes K. Critical appraisal of qualitative research. In: Noyes J, Booth A, Hannes K, Harden A, Harris J, Lewin S, Lockwood C, editors. Supplementary guidance for inclusion of qualitative research in Cochrane systematic reviews of interventions, version 1 [online]. NK: Cochrane Collaboration Qualitative Methods Group; 2011.

31. Ritchie J, Spencer L. Qualitative data analysis for applied policy research. In: Bryman A, Burgess RG, editors. Analysing qualitative data. London: Routledge; 1994. p. 173-94.

32. Tonna A, McCaig D, Diack L, West B, Stewart D. Development of consensus guidance to facilitate service redesign around pharmacist prescribing in UK hospital practice. Int J Clin Pharm. 2014;36(5):1069-76.

33. Jorgenson D, Laubscher T, Lyons B, Palmer R. Integrating pharmacists into primary care teams: barriers and facilitators. Int $\mathbf{J}$ Pharm Pract. 2014;22:292-9.
34. Weir N, Newham R, Dunlop E, Bennie M. Factors influencing national implementation of innovations within community pharmacy: a systematic review applying the Consolidated Framework for Implementation Research. Implement Sci. 2019;14:21.

35. Ramos SF, Santos Júnior GAD, Pereira AM, Dosea AS, Rocha KSS, Pimentel DMM, Lyra-Jr DP. Facilitators and strategies to implement clinical pharmacy services in a metropolis in Northeast Brazil: a qualitative approach. BMC Health Serv Res. 2018;18:632.

36. Zaidan M, Singh R, Wazaify M, Tahaineh L. Physicians' perceptions, expectations, and experience with pharmacists at Hamad Medical Corporation in Qatar. J Multidiscip Healthc. 2011;4:85-90.

37. Hindi A, Schafheutle E, Jacobs S. Patient and public perspectives of community pharmacies in the United Kingdom: a systematic review. Health Expect. 2018;21:409-28.

38. Jebara T, Cunningham S, Maclure K, Pallivalapila A, Awaisu A, Al Hail M, Stewart D. A modified-Delphi study of a framework to support the potential implementation of pharmacist prescribing. Res Social Adm Pharm. 2019. (in press). https://www.scien cedirect.com/science/article/pii/S1551741119306953. Accessed 11 Nov 2019.

Publisher's Note Springer Nature remains neutral with regard to jurisdictional claims in published maps and institutional affiliations. 